Western University

Scholarship@Western

Aboriginal Policy Research Consortium International (APRCi)

2008

\title{
The great divide in cancer care continues to fail Aborigines
}

Georgina Kenyon

Follow this and additional works at: https://ir.lib.uwo.ca/aprci

Part of the Health Services Administration Commons, and the Other Public Health Commons

Citation of this paper:

Kenyon, Georgina, "The great divide in cancer care continues to fail Aborigines" (2008). Aboriginal Policy Research Consortium International (APRCi). 227.

https://ir.lib.uwo.ca/aprci/227 


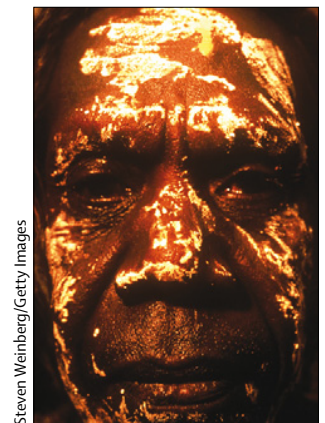

For more on Cancer in Indigenous people in Australia see Review Lancet Oncol 2008; 9: 585-95

For the CCQ research see Med J Aus 2011; 195: 350-54

\section{The great divide in cancer care continues to fail Aborigines}

Amnesty International is highly critical of the Australian Government and its failure to provide basic health services to remote Aboriginal communities, meaning that cancer care is out of reach to most Aborigines living traditional lifestyles outside cities.

"The Australian Government's failure to provide basic services to remote Aboriginal communities is a significant blight on Australia's human rights record and must be immediately addressed", says Amnesty International Secretary General, Salil Shetty, on a visit to the Utopia region in the Northern Territory in October-a desert region $240 \mathrm{~km}$ northeast of Alice Springs.

"What I sawwasjust devastating", said Shetty. "The fact that people are living with no running water, toilet, shower, and electricity in one of the richest countries in the world is completely unacceptable." About 1500 Aboriginal people live in communities along the Sandover River in Utopia. Most people in Utopia speak Aboriginal languages and some English. Traditional cultures are very strong in this region.

Shetty said that treatment of people in a wealthy country like Australia was shocking. "By stripping funding to communities living on their traditional lands, the Australian Government is effectively forcing these people to choose which of their rights they will forfeit", she said. "The right to live on their traditional land, or the right to basic and essential services like housing, health, and education." Shetty was also critical of the government for not including the Aboriginal community in its decision-making about the allocation of funding or planning, and calls for Aborigines to be involved in policy making.

According to the Australian Bureau of Statistics, cancer is the third most common cause of death for indigenous Australians and accounts for a greater number of deaths than does kidney and liver disease. Preventable cancer deaths are also higher in Indigenous
Australians than in the Australian general population. Although funding by the Australian government's Department for Health and Ageing for preventative cancer projects in Indigenous communities has increased during the past 5 years, assessment and monitoring of such programmes have been poor, and analysis of why they are not effective in some communities has been scarce. Because the rate of diagnosis of cancer in Aborigines is poor, analysis of the disease is complicated and sometimes misleading because of a lack of data.

Amnesty's criticisms come at a time when health campaigners are critical of cancer care in remote areas for al Australians. Cancer radiation services are so poor in regional centres across Australia that survival rates from cancer are now partly dependent on whether a person lives in the countryside or near a capital city. Cancer campaigners say that people who live in rural areas have to pay for private treatment just to complete their cancer care.

For example, research from the Cancer Council Queensland (CCQ), showed that the mortality risks for people diagnosed with rectal cancer in Queensland increases, on average, by $6 \%$ for every $100 \mathrm{~km}$ in distance a person lives from a radiotherapy centre. The researchers recommended an increase in travel and accommodation assistance for regional cancer patients.

"Evidence has found that the perception of significant out-of-pocket costs can contribute to suboptimal treatment decisions or non-compliance with medical recommendations, and that financial distress has a significant influence on patients' decisions about treatment and recovery", said CCQ's Chief Executive Officer, Jeff Dunn.

However, Aborigines have worse rates of cancer and are more likely to die from the illness largely because of their lifestyle, a lack of funding, and because they are diagnosed with the disease too late. lan Olver (Cancer
Council Australia, Sydney, Australia) explained that smoking and obesity is high in Aborigines. "This means that Aborigines often develop cancers with poorer outcomes, such as lung and head and neck cancer", he said. "These cancers are over-represented among Aborigines compared with the nonindigenous population."

Also, screening services for cancer are poor in Aboriginal communities. There is usually little provision of services such as the national BreastScreen and cervical cancer Pap smear programmes. "This results, for example, in Aboriginal women being five times as likely to die of cancer of the cervix," he said "Remoteness is also associated with inferior outcomes for many cancers in the general population and this applies to many indigenous people." On average, Aborigines are less likely than other Australians to live near the best health-care services.

Freddy Sitas, Director of the Cancer Research Division at Cancer Council (New South Wales [NSW], Australia) explained that remoteness is a problem for cancer care for Aborigines in Australia, not just in the Northern Territory. "The location of treatment facilities, limited childcare facilities, lack of proper transport, and simply living too far away from medical care facilities or the feelings of isolation while undergoing treatments are all factors that mean that Aboriginal people living in NSW being three times more likely to die from some cancers than other people living in the NSW area."

Cancer Council's NSW is researching how to tackle these issues and get more information from Aboriginal people about the problems they are facing to access treatment. "We need to find these answers to develop strategies aimed at reducing the cancer death rate gap that exists for Aboriginal people in NSW", Sitas concluded.

Georgina Kenyon 